\title{
A Comparison of Chinese and British Tea Culture
}

\author{
Ni Wang \\ School of Language, Literature and Law, Xi'an University of Architecture and Technology \\ No. 13 Yanta Road, Xi'an 710055, China \\ Tel: 86-29-8220-1048Ｅ-mail: 105487568@qq.com
}

Received: February 15, $2011 \quad$ Accepted: March 14, $2011 \quad$ doi:10.5539/ach.v3n2p13

\begin{abstract}
As an old and traditional beverage, tea has been an important part of people's life in both China and the United Kingdom (UK), and has respectively developed a unique culture in each of the two nations. Tea culture is an important part in culture of these two nations. In this paper, the author will first review 3 important aspects of the tea culture in China and the UK: history of tea, tea drinking customs and teasets, and then a conclusion about the similarities and differences of Chinese and British tea culture will be drawn.
\end{abstract}

Keywords: Chinese tea culture, British tea culture, Afternoon tea, Tea art, Teasets, Tea drinking customs

\section{Introduction}

Being an old and traditional beverage, tea was first grown in China and then spread to other countries and has always been liked by people all over the world. Despite the increasing market share of modern drinks such as soft drinks and alcohol drinks, tea has never lost its popularity, especially in recent years, when people are increasingly aware of the importance of organic foods and drinks, tea is being considered one of the most natural and healthy drinks which is promoted by more and more people around the world.

Tea culture, one of the most interesting and popular topics on tea, has long been talked and discussed by people from different countries, among which, China and the UK are two large tea drinking nations. With its long history in each of the two nations, tea has respectively developed a unique culture in them. Chinese tea culture and British tea culture, being two popular topics in culture, have been discussed by the academia in the two countries. However, the comparison of these two tea cultures has not been made sufficiently, and even when this topic is discussed, in most cases the differences are the focus, but not the similarities.

There is no doubt that the comparison of Chinese and British tea culture is an important and interesting topic in culture and cross-cultural communication, and this topic will be talked in this paper. In this paper, 3 important aspects of tea culture in the two nations will be reviewed, and in the conclusion, not only the differences but also the similarities of Chinese and British tea culture will be focused.

It is universally known that China is the original tea-growing area, as well as the first country to grow, produce and drink tea. A common Chinese saying runs, "When we get up in the morning, the first things we should get ready are firewood, rice, edible oil, salt, soy, vinegar and tea," which demonstrates tea is a necessity of life in China. According to the Holy Farmer's Herbal Classic, it was almost 3000 years ago when China found and started to use tea. Over the years, being more than a drink, tea has been well liked and developed in China. Moreover, it has spread to Japan, Korea, India, Central Asia, Arabian Peninsula and Europe. Chinese tea, like Chinese silk and china, made an outstanding contribution to the world's material and spiritual civilization.

In spite of its early discovery in Asia, tea was unknown to Europeans until the 16th century and was not introduced to Britain by the Dutch until the mid 17th century. Since then, tea has been an important drink in Great Britain for hundreds of years, and is drunk throughout the day in most British households. Nearly all British people drink an enormous quantity of cups of tea, and people in the north of England and Scotland can easily drink 10 to 20 cups of tea in average per day. Throughout the 300 years that the British have been drinking tea, it has had a remarkable influence on the nation's culture and lifestyle patterns through the ages. Tea has permeated British culture. 


\section{History of Tea in China and Britain}

\subsection{The discovery and the use of tea in China}

The discovery of tea in China can be traced back to the ancient time of Holy Farmer, who was thought as the God of Farming and Medicine. It is said that one day he got poisoned 72 times when gathering and tasting herbs on a mountain. Later he found a plant (tea) and brewed the leaves in a pottery tripod and drank the liquid. As a result, the toxins in his body disappeared. Since then, tea was treated as a precious medicine and later a vegetable and was specially used as a magical drink among a group of high-level scholars in the Han Dynasty (206B.C.-A.D.220). However, it was not until the Tang Dynasty (618-907) did the real Chinese tea culture, including tea art, the tea ceremony and a complete expression of cultural philosophy come into being.

In the Tang Dynasty, the tea plant was cultivated in 42 prefectures of China, and the habit of drinking tea had filtered into the daily life of people of all social ranks and classes. (Wang, 2000, p. 13)

\subsection{History of tea in Britain}

\subsubsection{Tea arrives in Britain}

"The first western reference to tea was in a 1559 volume of travel literature entitled Voyages and Travels, compiled by Giambattaista Ramusio. It describes tea as a hot drink with medicinal qualities. In spite of the early reports of tea, the Portuguese and Dutch traders did not bring it to Europe until 1610." (Tea Comes to England, 2005)

The early beginnings of tea in Britain are obscure. The East India Company, under their charter granted by Elizabeth I to the Directors, had the monopoly of importing goods from outside Europe and recorded ships reaching Britain in 1637, but no record of tea dealings with Chinese merchants appears until 1644. Sailors bringing back packets of tea from the Far East as gifts, led to its introduction into London's coffee houses. (Tea Comes to England, 2005)

\subsubsection{Tea gains popularity in Britain}

The merchant Thomas Garway was among the first to trade tea in Britain. He offered it in dry and liquid form at his coffee house in Exchange Alley in the City of London, holding his first public sale in 1657.

In 1660 , Garway issued a broadsheet selling tea for sale at $£ 6$ and $£ 10$ per pound. Garway claimed tea was "wholesome, preserving perfect health until extreme old age, good for clearing the sight," able to cure "gripping of the guts, cold, dropsies, scurveys" and claiming that "it could make the body active and lusty." (The British Tea Company, 2005)

The first tea advertisement--announcing the sale of "China Tcha, Tay or Tee"-- appeared on 30 September 1658, in the newspaper Mercurius Politicus, booked by the owner of The Sultaness Head Coffee House. "Tea rapidly gained popularity in these establishments and by 1700 , was on sale by more than 500 coffee houses in London. Tavern keepers were dismayed as the coffee house vogue swept into being, as was the Government by the decline in revenues from hard liquor sales." (The British Tea Company, 2005) "By the middle of the 18th century, however, tea had replaced ale and gin as the drink of the masses and had become Britain's most popular beverage." (The British Tea Company, 2005)

\section{British and Chinese Tea Drinking Customs}

\subsection{British tea drinking customs}

\subsubsection{Afternoon tea}

This is the one that comes to mind when people think of British tea ceremonies. Anna, the 7th Duchess of Bedford is often credited with the invention of the tradition of afternoon tea in the early 1840's. Traditionally dinner was not served until 8:30 or 9:00 in the evening and the Duchess often became hungry, especially in the summer when dinner was served even later. She ordered a small meal of bread, butter, and other niceties, such as cakes, tarts, and biscuits, to be brought secretly to her boudoir. Later she found that she was not ridiculed, as she had feared, but her habit caught on and the concept of a small meal, of niceties and perhaps tea, became popular and eventually known as "afternoon tea". In those days only the wealthy could afford to buy tea. They would invite guests to their houses and the tea-drinking ceremony would begin. The host would bring out the finest porcelain called china, which was extremely thin, fragile and intricately painted, and the beverage would be served, along with delicate thin sandwiches of cucumber and ham, plus cakes, scones, cream, clotted cream, and jam. The emphasis was on presentation and conversation. Obviously the origins of the well known British tradition of afternoon tea cannot be credited to only one woman, but evolved over a period of time, as many 
cultural customs do. (Polite society, 2005)

An English-style afternoon tea is traditionally served between 2 p.m. and 4 p.m. and typically lasts about one and a half to two hours. Traditional afternoon tea consists of a selection of dainty sandwiches (including thinly sliced cucumber sandwiches), scones served with clotted cream and preserves. Cakes and pastries are also served. Tea grown in India or Ceylon is poured from silver tea pots into delicate bone china cups. Nowadays however, in the average suburban home, afternoon tea is likely to be just a biscuit or small cake and a mug of tea, usually produced using a teabag. It can be formally served in the dining room or at the living room tea table. Informal teas can be enjoyed in the kitchen, garden, as a picnic, or any location of choice. Nowadays, however, afternoon tea is mostly taken not in people's houses, but in the many quaint tearooms which can be found the length and breadth of the Britain. A favorite place for friends, mothers and daughters to get together for chat and quality time together, tea rooms provide an intimate, relaxed atmosphere conducive to friendly banter and shared confidences. (Polite society, 2005)

\subsubsection{High tea}

For the working and farming communities, afternoon tea became high tea. The high tea evolved to take the place of dinner when a proper hot meal could not be afforded. High tea was a family meal, and took place anytime between 5:00 and 7:00 pm. It was much larger than the few sandwiches and pastries eaten for an afternoon tea in the bourgeoisie. One or two small hot dishes were served along with cold chicken, game, or ham, salad, and cakes or tarts. It was more of a man's meal, than a ladies social diversion. (Polite society, 2005)

\subsubsection{Tea breaks}

Tea breaks are a tradition which has been with the Britons for approximately 200 years. Initially when workers commenced their day at around 5 or 6 am, employers allowed a break in the morning when food and tea were served. Some employers repeated the break in the afternoon as well.

Tea, for the working class was a substance that constituted a break from work, just as many office workers in the United States have cigarette or coffee breaks. It was a brief time of rest to socialize with other workers, and collect the energy to finish the day. Not only was it a break from work, but the caffeine and sugar in the hot tea gave the impression that one had eaten something. (Tea Comes to England, 2005)

\subsection{Chinese tea art and drinking customs}

\subsubsection{Tea art}

The spirit of tea art and the tea ceremony is the core of Chinese tea culture. "Art" refers to techniques and artistic process of making, cooking and tasting tea, while ceremony refers to the spirit with which the process is carried out. (Wang, 2000, p. 40) "Artistic tea" means to regard the process of planting, picking, making and selecting tea as an artistic enjoyment.

First, tea growers should select the right places to plant tea trees.

Second, the picking of tea is very important. The picking time became very strict in the Song Dynasty. The best time was between the Waking of Insects and Pure Brightness. Tea is picked with the nails instead of the fingers so that its quality is not affected the hand's temperature. The hands' movements of the picking tea women are like beautiful dance movements. (Wang, 2000)

Third, the process of making tea is also an artistic procedure. In the Tang Dynasty, there were four varieties of tea: weak tea, loose tea, tea dust and tea cakes.

Additionally, excellent water is essential for the best tea. According to Lu Yu's the Book of Tea, the water used to brew tea should be different from ordinary drinking water. Water from mountains was the best, river water was inferior, and well water was low grade. Dew drops from mountain stalactites, clear flowing springs and clear river streams were regarded the sources of the best water for brewing tea. (Wang, 2000)

\subsubsection{Tea drinking customs}

The Chinese popular tea drinking customs is quite different from the British ones.

As an art, tea drinking requires a special environment. In ancient times there were many participants in large tea parties and imperial tea feasts. However, according to the theory of traditional Chinese tea ceremony, it is unnecessary to have many participants. The theory required one to drink tea in elegant environment, such as by clear springs or in bamboo groves on mountains, in ancient temples and small pavilions, or in one's own garden while appreciating flowers, snow or fish. Generally speaking, the tea's quality, the drinkers' moral quality and the environment should harmonize. (Wang, 2000, p. 45) People could let nature take its course while a whole family or a couple drink tea at home. 


\section{British and Chinese Teasets}

\subsection{British teasets}

\subsubsection{Tea bags}

The invention of the tea bag is said to have resulted from the small silk sample bags used by Thomas Sullivan, a New York City tea merchant, in 1908 to send out to potential customers. However the 1920's is said to have been the "decade of the teabag", and its commercial use developed from the tea egg or tea ball (a perforated metal container on a chain) into a tea bag. (British Tea Drinking Customs, 2005)

The first bags were made from cloth or gauze and were so described and illustrated Ukers in 1935, around 1935 Messrs Joseph Tetley who had a powerful associate company in the States made a tentative approach to market teabags in the UK. Initial acceptance was slow but Tetley never gave up. The teabag market eventually began to grow in the UK in the 1960's when approx 5\% of tea was consumed in bags. By 1965 it had risen to 7\% and now, $85 \%$ of tea consumed in the UK is done so with teabags. (British Tea Drinking Customs, 2005)

\subsubsection{Tea and the British porcelain industry}

The earliest tea cups had no handles, being originally imported from China where cups traditionally were more like small beakers. As tea drinking gained popularity, so did the demand for more British-style tea ware. This fuelled the rapid growth of the English pottery and porcelain industry, which soon became world famous. Most factories making tea ware were located in the Midlands area which became known as "The Potteries". (British Tea Drinking Customs, 2005)

\subsubsection{Tea pots}

In the earliest history of tea drinking, tealeaves were simply boiled in open pans. It was the Ming Dynasty that led the fashion for 'steeping' the leaves and therefore led to the need for a covered pot that would allow the leaves to infuse and keep the liquor hot. Ewers, resembling the modern teapot, that for centuries had been used for wine were now adapted to tea brewing. (Tea Comes to England, 2005)

By the time the Dutch started carrying cargoes form China back to Europe, the concept of the teapot had developed further, the teapots that they brought back were small, with broad bases and wide spouts, which would not clog easily. As Europe had never seen such Chinese stoneware, it took Dutch potters until late 1670's to reproduce the heat-resistant pots. Two of The Netherlands' most successful potters the Elers brothers settled in Staffordshire and established the English Pottery industry. (Tea Comes to England, 2005)

\subsubsection{Tea caddies}

The first containers used for the domestic storage of tea were the jars and bottles that arrived from China with shipments of tea. Gradually, European jars and boxes were developed in a wide range of shapes and sizes - round, square and cylindrical boxes, jars and bottles, in silver, crystal, stoneware and wood. The word "caddy" was not used until the end of the eighteenth century when the word kati - denoting a measure of approximately 1 pound and 5 ounces - was adopted into English. (British Tea Drinking Customs, 2005)

Early eighteenth century boxes, called tea chests, had two or three separate compartments for different teas and sometimes also for sugar. All were lockable, and the lady of the house guarded the keys. As tea was far too precious and expensive to risk leaving in the charge of the servants, the caddy stayed in the family drawing room. (British Tea Drinking Customs, 2005)

The Chinese had started producing fruit shaped containers earlier in the eighteenth century, and English and German wooden imitations appeared as pears, apples, strawberries, eggplants and pineapples. Some were painted but most were varnished and their loose-fitting, hinged lids opened to reveal foil-lined cavity that held the tea. As the price of tea decreased toward the end of the nineteenth century, the use of lockable caddies and ornate jars declined as tealeaves were transferred to practical tins and boxes that were stored in the kitchen. (British Tea Drinking Customs, 2005)

\subsubsection{Tea spoons}

The earliest caddy spoons were long-handled ladles made for use with box-like tea chests. From about 1770 , short-stemmed caddy spoons began to appear, designed to fit into shorter, dumpier caddies and often in the form of a miniature scallop shell. This motif originates from the fact that oriental merchants always placed a real scallop shell in the top of tea chests to allow potential buyers to take a sample from the chest before deciding to buy. (The British Tea Company, 2005)

Spoons have been manufactured in the form of leaves, acorns, salmon, thistles and shovels but the most popular 
has always been the shell, the jockey's cap, the hand and the eagle's wing. The "caddee shell" motif also often appears on teaspoons, tea strainers and sugar tongs. (The British Tea Company, 2005)

\subsection{Chinese teasets}

According to Lu Yu in his Book of Tea, there are 24 vessels, including:

1. Windstove: Used to make fire to brew tea.

2. Bamboo basket: A square basket woven in bamboo filigree used to pick tea.

3. Charcoal seizer: The ancients uesd charcoal to brew tea, and believed that tea's quality would vary with the type of fire.

4. Fire-clip: Used to brew a tea.

5. Boiler: Used to brew a tea.

6. Wooden stand: To place a boiler with a stove underneath.

7. Paper bag: To keep brewed tea so that the fragrance would not be let out.

8. Tea roller and tea dust cleaner: the former was used to grind tea, and the latter, to clean tea dust off the roller.

9. Tea basket: To sift tea.

10. Ze: To measure tea.

11. Water container: To store unboiled water.

12. Filter bag: To filter tea water.

13. Ground ladle: To ladle out water.

14. Bamboo clip: To stir tea water to give full play to tea's properties

15. Salt stand: To hold salt powder.

16. Processed jar: To store hot water.

17. Bowls: Necessary implements for tasting tea.

18. Ben: To store bowls.

19. Zha: To water the vessels. It was similar to a pot-scouring brush.

20. Water collector: To store water.

21. Dregs collector: To gather tea dregs.

22. Cloth: To clean the vessels.

23. Teasets stand: To display a teaset.

24. Big basket: To store all the vessels after drinking tea.

These complicated vessels were necessities for the ancients to perform and perfect the ritual of drinking tea. A person could also change his mood and temper his practical ability through using the vessels. (Wang, 2000)

\section{Conclusion}

Generally speaking, both Chinese and British tea culture were initiated in high social class and filtered into the daily life of people of all social ranks and classes. Both Chinese and Britons consider tea a traditional and natural beverage that could bring them relaxation and enjoyment and like to drink tea at parties and feasts.

Britons are concerned more about the variety and taste of tea while Chinese pay more attention to the purity and quality. Instead of drinking pure tea, Britons have added milk, sugar, fruit, flowers and even spice to tea. In addition, sandwiches, scones, cookies and a special dessert such as a fruit tart or a rich cake are also served with tea. Moreover, Chinese associate tea with their traditional cultures, such as poetry, painting, calligraphy and even religions like Taoism, Confucianism and Buddhism.

While the twentieth century brought innovation to tea, including teabags, instant tea and canned tea, tea has become not a mere beverage, but an important part of Chinese and British culture. 


\section{References}

British Tea Drinking Customs. (2005). [Online] Available: http://www.tea.co.uk/tGloriousT/tcustoms.htm (January 1, 2010).

Polite society. (2005). [Online] Available: http://www.twinings.com/en_int/history_tradition/polite.html (January 2, 2010).

Tea Comes to England. (2005). [Online] Available: http://www.panix.com/ kendra/tea/bibliography.html (January 7, 2010)

Tea Gardens. (2005). [Online] Available: http://www.tourismvictoria.com/Content/EN/597.asp (January 2, 2010).

The British Tea Company. (2005). Tea in Britain. [Online] Available: http://www.Thebritishteacompany.com/about_hist_britain.php\#top (January 7, 2010).

Wang, L. (2000). Chinese Tea Culture. Beijing, China: Foreign Language Press. 